\section{La "anarquía" de la} leche: ciencia, calidades e infraestructuras alimentarias en Bogotá, 1938-1960

\section{Milk "anarchy": food science, quality and infrastructures in Bogotá, 1938-1960}

POHL-VALERO, Stefan. La "anarquía" de la leche: ciencia, calidades e infraestructuras alimentarias en Bogotá, 1938-1960. História, Ciências, Saúde Manguinhos, Rio de Janeiro, v.28, n.4, out.-dez. 2021, p.1221-1242.

\section{Resumen}

Este artículo analiza las lógicas, intereses y contingencias presentes en los intentos de expertos y legisladores por fomentar e higienizar el sistema lechero en la ciudad de Bogotá, entre 1938 y 1960. Estos esfuerzos se enmarcaron en una arquitectura institucional que iba de lo municipal a lo nacional, y en un contexto de creciente intervención del Estado en cuestiones nutricionales y de proyectos internacionales de cooperación técnica en salud. A pesar del fracaso en mejorar la calidad de la leche y aumentar su consumo, este estudio de caso nos muestra los efectos de una legislación poco adaptada a las circunstancias locales en la infraestructura material del sistema y los intereses comerciales detrás de las normativas de calidad del producto.

Palabras clave: higienización de la leche; calidad de los alimentos; cooperación técnica; historia; Bogotá.

\section{Abstract}

This article analyzes the logics, interests and contingencies present in experts' and legislators' attempts to develop and sanitize the dairy system in the city of Bogotá, from 1938 to 1960. These efforts were framed by an institutional architecture from the municipal to the national level, and a context of increasing state intervention in nutrition issues and international technical cooperation on health projects. Despite the failure to improve milk quality or increase milk consumption, this case study shows us the effects of legislation that was ill-adapted to local circumstances in terms of the material infrastructure of the system and the commercial interests behind product quality regulations.

Keywords: milk sanitation; food quality; technical cooperation; history; Bogotá. 
A partir de la década de 1930 se incrementaron los esfuerzos oficiales - nacionales y municipales - por regular y fomentar el sistema lechero en varias ciudades de América Latina. Esta preocupación reflejó un complejo entramado de saberes, instituciones y expertos - locales e internacionales - que luchaban por aumentar la producción y el consumo de leche de vaca, así como por asegurar las condiciones higiénicas y sanitarias de este producto perecedero. Como ha señalado la historiografía de la leche en la región, esta creciente intervención experta en el sistema alimentario del líquido blanco se puede inscribir tanto en el horizonte político de los esfuerzos de los gobiernos latinoamericanos de la época por promover un incipiente estado de bienestar y de desarrollo económico, como en el horizonte científico y cultural que construyó la percepción de que la leche de vaca era el alimento perfecto para el ser humano en todas sus edades y que su consumo era un indicador de civilización y progreso (Birn, 2008; Aguilar-Rodríguez, 2011; Zazueta, 2011; Brinkmann, 2014, 2021; Goldsmith Weil, 2017; Buschini, 2018).

En Bogotá, aunque desde principios del siglo XX existía legislación sobre normas de sanidad que debía seguir la producción, transporte y expendio de la leche, fue también en la década de 1930 cuando su sistema lechero empezó a ser estudiado e intervenido de forma más sistemática por las autoridades locales (Rojas, Ibáñez, 1919; Castro, 1944). En un principio, estos esfuerzos se centraron en los aspectos de la producción para lograr la higienización de la leche, pero frente a la dificultades y elevado costo de vigilar un creciente número de hatos que enviaban su producto a la ciudad, a finales de la década de 1930, la legislación pareció orientarse a fomentar la pasteurización y su centralización como medida complementaria y prioritaria (González, 1952). Sin embargo, a lo largo de las décadas de 1940 y 1950, los intentos de municipalizar, centralizar y/o hacer obligatoria la pasteurización de la leche no se lograron (Cavelier, 1947; Steiner, 1950; Turriago Romero, 1955), a la vez que los análisis fisicoquímicos y bacteriológicos del producto (tanto crudo como pasteurizado) indicaban que su calidad era pésima (Camacho Gamba, 1934; Castro, 1944; Cedeño Saavedra, 1959).

De forma paralela, la lechería se había convertido en la "industria pecuaria más importante de la Sabana de Bogotá" (Román, 1946, p.42) gracias, en parte, a que el clima frío de esta gran meseta que rodea la ciudad facilitaba la adaptación de razas vacunas europeas de alta producción. Algunos agrónomos vislumbraban la Sabana de Bogotá como un centro productor de leche con gran potencial y destinado a resolver el "grave problema de la desnutrición de nuestro pueblo tan pobremente alimentado" (p.42). No obstante, en la década de 1950, la producción de leche en la Sabana no había logrado realmente optimizarse. La posibilidad de que esta región se convirtiera en la "zona lechera de Colombia", pudiendo tecnificarse y enviando a otras regiones del país productos lácteos no parecía poder lograse en el futuro cercano, opinaba un agrónomo en 1953. El minifundio excesivamente "primitivo" y, sobre todo, "los problemas de tenencia de tierras" eran las razones aducidas para esta situación (Beltrán, 1953, p.16-17).

Por su parte, el consumo promedio de leche de vaca por habitante de la ciudad apenas aumentó entre 1939 y 1954 (Bogotá, 1940-1951; Colombia, 1952-1954). El pequeño vaso de leche que la población bogotana consumía al día estaba muy por debajo de las recomendaciones nutricionales de la época (Góngora López, 1953, p.215). Y aún más 
apremiante y paradójico era que, a pesar de los numerosos intentos por asegurar la calidad higiénica de la leche, todavía en la década de 1950 se le denominaba el "veneno terrible", en tanto que seguía siendo considerada como vector importante de enfermedades infecciosas y causa principal de la mortalidad infantil en la ciudad (Cedeño Saavedra, 1959, p.12; Muñoz, Pachón, 1988).

Como quiero mostrar en este artículo, más allá de los ideales de progreso y salud en torno a los discursos médicos y prácticas higiénicas de la época (Noguera, 2003), el caso bogotano del problema de la leche a mediados del siglo XX (1938-1960) pone de manifiesto las profundas complejidades a la hora de estructurar un sistema alimentario específico y la naturaleza fracturada y contingente de las intervenciones expertas destinadas a fomentar la producción y el consumo de leche, así como a asegurar la calidad higiénica del producto a lo largo de la cadena de suministro - desde el hato hasta el vaso. Durante esa época las intervenciones en el sistema lechero se caracterizaron por una legislación que en muchos casos intentó implementar normativas copiadas de otros países sin tener en cuenta las posibilidades reales de su aplicación, por varias tensiones entre expertos y autoridades sobre cómo lograr la higienización de la leche y por una serie de instituciones involucradas en la cuestión alimentaria - que iban de lo municipal y nacional a lo internacional - poco coordinadas entre sí y con intereses y objetivos diversos. Todo esto repercutió en un sistema que no logró producir y distribuir leche de buena calidad, pero cuya legislación terminó fomentando que existieran diferentes tipos de leche en el mercado de Bogotá (cruda, enfriada, pasteurizada, hervida). Estos tipos de leche se inscribieron en sistemas de clasificación y suministro diferenciados, los cuales se relacionaron con circuitos comerciales de infraestructuras tecnológicas específicos.

Las profundas tensiones entre los diversos actores del sistema lechero de Bogotá, la incapacidad para lograr su higiene y la diversidad de infraestructuras tecnológicas requeridas por la cambiante legislación se hicieron evidentes a principios de la década de 1950, cuando se intentó implementar un nuevo código nacional de leches y se creó el Consejo Nacional de Leches. A raíz del rechazo de este código por parte de las autoridades municipales de higiene de Bogotá, en 1952, el funcionario del ministerio de agricultura y ganadero de la Sabana de Bogotá Pedro Navas Pardo no dudó en señalar que:

Es la misma historia de siempre: cada director de higiene viene y legisla sobre leches y el que lo sustituye echa luego todo atrás. Desde hace veinte o treinta años en Bogotá, estamos viendo las continuas experiencias de los distintos funcionarios, y la realidad es que no hay higiene en el mercado de leches. Esto, naturalmente, incide en forma inmediata sobre el mercado que se mantiene en constante anarquía. La improvisación en materia de legislación de leches es algo que nadie puede negar. Un director de higiene establece la cortina de enfriamiento y el que lo sustituye en el puesto cambia ese sistema e impone la pasteurización; otro cambia los dos sistemas y dice que la mejor manera de tomar leche higiénica es vendiéndola cruda. Y al final de todo eso, nadie sabe a qué atenerse, y los productores nunca alcanzan a entender cuál es la mejor manera de orientarse en el negocio (El problema..., 20 ago. 1952, p.1).

Este artículo hace un esfuerzo por abordar en un mismo campo de análisis los múltiples eslabones de la cadena de suministro de la leche y los heterogéneos intentos de intervención 
de expertos a lo largo de su transcurso, cuestión que ha sido prácticamente inexplorada por la historiografía colombiana (Álvarez Múnera, 2016). ${ }^{1}$ Por lo general, el tema de la leche de vaca ha sido abordado tangencialmente ya sea desde perspectivas económicas preocupadas por el desarrollo agrícola - con un énfasis en la producción y los datos estadísticos - o desde perspectivas sociales y culturales preocupadas por la historia de la infancia, la medicalización de la alimentación y por los proyectos de ingeniería social de la época - con un énfasis en el consumo y los discursos científicos (Muñoz, Pachón, 1988; Kalmanovitz, López Enciso, 2006; Pohl-Valero, 2014; Márquez Valderrama, Gallo Vélez, 2017). Además de un intento por contribuir a llenar este vacío historiográfico, el presente estudio de caso destaca cómo la historia material de un producto alimenticio se puede articular de manera provechosa con la historia de la ciencia y la salud para entender con mayor complejidad la configuración histórica, las intervenciones de gobierno y sus alcances efectivos (Atkins, 2010; Pohl-Valero, 2020; Pohl-Valero, Vargas, 2021).

La vía metodológica que persigo en este artículo consiste en preguntarse por las definiciones de la calidad de los alimentos como puerta de entrada para analizar la forma como se ensamblan sistemas alimentarios específicos (Atkins, 2011). Además de explorar el "por qué" y el "cómo" del consumo de leche - más que asumirlo como algo autoevidente (DuPuis, 2002, p.6) -, la pregunta sobre la definición y reglamentación de las calidades de leche y sus efectos en la cadena de suministro de la época nos invita justamente a rastrear las múltiples trayectorias de la leche, desde el hato hasta el vaso, y en consecuencia a ampliar y conectar diversas fuentes primarias y transitar por diversas escalas de análisis. Para esto, se exploró un corpus documental diverso que incluyó publicaciones de higienistas, pediatras, nutricionistas, veterinarios, agrónomos y pasteurizadores, así como legislación e informes municipales y nacionales. Sigamos entonces en las próximas páginas, y de forma panorámica, los "ríos de leche" que surcaron la historia de Bogotá en un momento de expansión y modernización de la ciudad, de creciente intervención del estado en cuestiones alimentarias y de proyectos internacionales de asistencia alimentaria y cooperación técnica (Pohl-Valero et al., 2021).

\section{Leches en el papel: discursos, legislación y calidades}

A principios del siglo XX los médicos colombianos empezaron a articular la reciente ciencia de la bacteriología con los desarrollos de la fisiología de la nutrición, lo cual ayudó a estructurar un nuevo horizonte interpretativo sobre la relación entre salud y alimentación, y vislumbrar diversas estrategias de ingeniería social para el mejoramiento racial (Noguera, 2003; Pohl-Valero, 2014; García, Pohl-Valero, 2016; Márquez Valderrama, Gallo Vélez, 2017). Bajo este horizonte, los alimentos empezaron a ser concebidos como la cantidad de energía que requería el cuerpo humano para su adecuado funcionamiento, a la vez que su calidad incluyó tanto aspectos químicos y físicos relativos a los procesos metabólicos, como bacteriológicos relativos a las enfermedades infecciosas.

La cantidad de calorías, nutrientes y vitaminas presentes en la leche de vaca la posicionaba como uno de los mejores y más completos alimentos disponibles en la naturaleza. En este sentido, los expertos locales empezaron a fomentar su consumo, el cual se interpretó como 
una de las principales estrategias para lidiar con el problema nutricional del país, para combatir el alcoholismo, e incluso para asegurar la democracia (Bernal, 1932; Bejarano, 1941, p.36-43; Molano Campuzano, 1953a). Según estos expertos, la leche representaba la "despensa mágica" de la naturaleza (Saavedra, 1951, p.417), la demostración del talante "químico" del creador (Castro, 1944, p.107), la evidencia de que la vaca era el "laboratorio más perfecto que existe" (Bernal, 1932, p.3) y la encarnación del "alimento perfecto y completo para el hombre" (Saavedra, 1951, p.417).

No obstante, su calidad podía ser fácilmente alterada y contaminada. El descremado, aguado y adición de otras sustancias no solo engañaban económicamente al consumidor, sino que reducían drásticamente su ingesta de calorías y nutrientes. El estado de salud de las vacas, ordeñadores y expendedores, así como su grado de limpieza (y también el de los establos, utensilios y aguas utilizados), podían contaminar la leche y convertirla en un vehículo de transmisión de enfermedades como la tuberculosis, la difteria, la fiebre tifoidea y la escarlatina, entre otras. Pero, aunque las condiciones higiénicas y sanitarias fueran adecuadas, el carácter perecedero de la leche la convertía en un excelente caldo de cultivo bacteriano, cuyo número de colonias crecía exponencialmente a las pocas horas de su ordeño si no se mantenía a bajas temperaturas (Cuevas, 1924; Gómez Rueda, 1932; Camacho Gamba, 1934; Castro, 1944; Paredes Chaves, 1954).

En 1933, el gobierno colombiano, a través del Departamento Nacional de Higiene, elaboró una detallada normativa sobre las condiciones de higiene y salud que se deberían cumplir a lo largo de la cadena de suministro de la leche y una clasificación del tipo de leches que se podían consumir de acuerdo con su calidad (Resolución 134 de 1933 reproducida en Castro, 1944, p.164-179). Así, cada hato debía tener una inspección veterinaria periódica y toda persona que intervenía en la manipulación de la leche, desde su obtención hasta la entrega, tener un certificado de salud. También se estipulaba el tipo de establos que debían tener los hatos, los procedimientos de ordeño y tipos de utensilios que se debían emplear y sus procesos de esterilización, la forma de almacenar y transportar la leche y las temperaturas requeridas, y las características materiales de los expendios. Estos requerimientos de salud y sanidad se volvían más exigentes en la medida que aumentaba la clasificación de calidad de las leches. La calidad se determinaba a través de análisis fisicoquímicos y bacteriológicos. El primer análisis daba cuenta del grado de adulteración de una muestra (cantidad de grasa, agua, cenizas, acidez etc.), y el segundo del grado de contaminación (cantidad de colonias bacterianas por centímetro cúbico y presencia de gérmenes patógenos).

Gracias a las gestiones del higienista Jorge Bejarano, en 1939 el Concejo de Bogotá elaboró un acuerdo (Acuerdo 17 de 1939) sobre higiene de la leche en la ciudad que aprovechaba y expandía la normativa nacional de 1933 (Castro, 1944, p.101). Estos esfuerzos nacionales y municipales se enmarcaban tanto en el creciente interés del gobierno liberal de la época por promover una política intervencionista en temas alimentarios, como en el auge de la cuestión nutricional por parte de organismos internacionales de salud (Pohl-Valero, 2016; Buschini, 2021). De hecho, Bejarano había sido el presidente de la comisión organizadora de la décima Conferencia Sanitaria Panamericana, realizada en Bogotá, en 1938. En esta conferencia se le prestó especial atención al problema nutricional de la región y una comisión de alimentación presentó su primer informe en el encuentro (Pohl-Valero et 
al., 2021). Entre los miembros de la comisión se encontraba el químico estadounidense Elmer McCollum, quién había descubierto dos décadas atrás un nutriente en la grasa de la leche que denominó "vitamina A" y quién popularizó internacionalmente la idea de que los pueblos más civilizados y modernos eran los que más leche tomaban (Valenze, 2011, p.238-252). No era de sorprender entonces que en el informe de la comisión el tema de la leche fue central, aunque su exposición se centró en destacar su gran valor nutritivo y en recomendar el aumento de su producción y consumo en la región, apenas mencionando el intrincado problema de cómo lograr su higienización a lo largo de toda la cadena de suministro (OSP, 1938, p.904-921).

En todo caso, la conferencia de 1938 fue seguramente un catalizador para los intentos que se hicieron el siguiente año para mejorar la calidad de la leche en Bogotá. En particular, el acuerdo de 1939 dispuso que se otorgaran extensión de impuestos y tarifas reducidas de agua y luz a las plantas de pasteurización y a los expendios de leche que cumplieran con las normativas de higiene, así como la creación de un laboratorio y cinco inspectores dedicados "exclusivamente" al control sanitario y vigilancia del producto (Acuerdo 17 de 1939 reproducido en Castro, 1944, p.179-180). Adicionalmente, el Concejo de Bogotá comisionó al director de higiene de la ciudad para que viajara a EEUU y estudiara "el problema de la higienización de la leche" y destinó una partida presupuestaria para comprar ahí los equipos necesarios para construir el laboratorio de leches (Archivo..., 1939, p.507). El veterinario Jaime Castro fue la persona encargada de comprar estos equipos y fue el primer director de dicho laboratorio. Pero como recordará unos años después José González (1952, p.7), el dueño de una de las pasteurizadoras más antiguas de Bogotá, muchas de estas iniciativas habían sido infructuosas: "[el acuerdo de 1939] pretendió estimular la higienización de la leche por todos los caminos y formas imaginables, haciendo concesiones que no se efectuaron, exposiciones que no se llevaron a cabo y decretando premios que no se concedieron por las autoridades".

La experiencia de Castro como director del laboratorio de leches le permitió identificar una serie de dificultades adicionales a la hora de intentar regular y vigilar el sistema lechero a partir de normativas y disposiciones que eran "inadecuadas para el control oficial de tan importante alimento, porque no son el fruto de un previo reconocimiento del medio y fijación de constantes sino tomadas al azar sin fundamento cierto" (Castro, 1944, p.152). Con respecto a los aspectos fisicoquímicos de la calidad de la leche en Bogotá, Castro señalaba, por ejemplo, que las normativas nacionales y municipales en ocasiones se contradecían. En particular, mencionaba la "anarquía entre productores, distribuidores y autoridades" debido a las diferentes definiciones sobre los mínimos fisicoquímicos requeridos para tener leches aceptables. Estas diferencias generaban, según Castro (1944, p.122-123), que los productores prefirieran la normativa nacional, ya que les permitía vender un artículo de inferior calidad al mismo precio; y los consumidores la normativa municipal, ya que se les ofrecía leche de mejor calidad sin tener que pagar más.

Adicionalmente, algunas de las características fisicoquímicas de la leche que efectivamente emanaba de las ubres de las vacas de la Sabana de Bogotá no se correspondían con estas normativas. Por ejemplo, la disposición municipal de exigir un mínimo de 9,5\% de extracto desengrasado era imposible de cumplir dado que, de los hatos analizados por 
Castro, casi ninguno sobrepasa el valor de 8,5\%. Por el contrario, el mínimo de grasa exigido por la normativa nacional $(2,5 \%)$ era muy bajo respecto a los promedios analizados, lo cual fomentaba que "muchos [de los] traficantes en leches no desprecian la oportunidad para descremar hasta ajustar el producto al mínimum exigido" (Castro, 1944, p.150).

La cuestión de la contaminación parecía ser aún más apremiante. Además de encontrar en varias muestras presencia de gérmenes patógenos, en la mayoría el "tenor bacteriano" identificado (colonias de bacterias por centímetro cúbico) revelaba que las leches de Bogotá eran de muy mala calidad. Según la clasificación oficial, había tres calidades de leche cruda ("certificada", "higienizada" y "común") y, dos de pasteurizadas (tipo A y B), siendo la "certificada" y la "tipo A" las de mayor calidad. La leche "cruda certifica" y la "cruda higienizada" se podían consumir sin hervir (y debían tener un bajo número de colonias bacterianas), mientras que la "cruda común", por su alto tenor bacteriano, estaba destinada a usos industriales o requería ser hervida por el consumidor. La leche "pasteurizada tipo A" debía ser procesada a partir de leche cruda higienizada, y la "tipo B" a partir de leche cruda común (Resolución 134 de 1933 reproducida en Castro, 1944, p.169-174). En la práctica, esta clasificación no tenía mucho sentido, ya que las calidades de leche presentes en el mercado bogotano durante la década de 1940 apenas llegaban a ser cruda común y pasteurizada B, por lo menos si nos atenemos a los exámenes bacteriológicos realizados.

Los mejores hatos lograban producir leches con un tenor bacteriano inferior a los 100 mil por centímetro cúbico, pero en la gran mayoría el número de colonias bacterianas de su producto difícilmente baja de 1 millón por centímetro cúbico. Los expendios de leche cruda, incluso los de "certificada", vendían un producto que superaba con creces esta cifra y, de las tres pasteurizadoras de la ciudad, solo una producía leche con menos de 500 mil bacterias por centímetro cúbico (las otras dos superaban los 5 millones) (Castro, 1944, p.119-120, 125-150). No en vano un observador de la época indicaba que "con excepción de una pasteurizadora y de la magnífica leche de la hacienda 'El Rodeo', todas las demás leches que dizque pasan por la pasteurización salen lo mismo de contaminadas o tal vez hasta más que antes de la supuesta pasteurizadora" (Steiner, 1950, p.46). Adicionalmente, los cinco inspectores de leche existentes en Bogotá, como resultado del acuerdo de 1939, no daban abasto para vigilar la cadena de suministro, además de que carecían "en absoluto de los conocimientos e instrumentos" requeridos para su labor (Castro, 1944, p.150).

Mientras tanto, la organización sanitaria de la ciudad se iba transformando a la par que se iban modificando varias de sus tendencias demográficas. En 1947, Bogotá había sobrepasado el medio millón de habitantes (a principios de la década de 1960 se duplicaría esa cifra), y las estadísticas de mortalidad infantil empezaban finalmente a indicar un descenso que se mantendría en los siguientes años (hasta 1945, las muertes de niños menores de un año por cada mil nacimientos se habían mantenido en torno a las doscientas) (Colombia, 1952-1965, año 1963, p.35, 78; ver Figura 1). No obstante, el consumo de leche seguía siendo considerado por las autoridades sanitaras como "uno de los factores primordiales de la mortalidad infantil, tan alta en Bogotá" (Cavelier, 1947, p.575). Además de recomendar que se hirviera la leche, incluso la pasteurizada, el gremio de pediatras empezó a señalar que se debería fomentar la producción de leche en polvo como estrategia para disminuir la mortalidad infantil. En 1948, uno de los centros de 
higiene de la ciudad reemplazó la leche fluida que obtenía de un hato de la Sabana por "leche en polvo de fabricación nacional" para alimentar a los niños del jardín infantil, sala cuna y gota de leche de dicho centro. El número de infantes enfermos por diarreas y enteritis disminuyó de "forma muy apreciable" (Protección..., 1948, p.14).

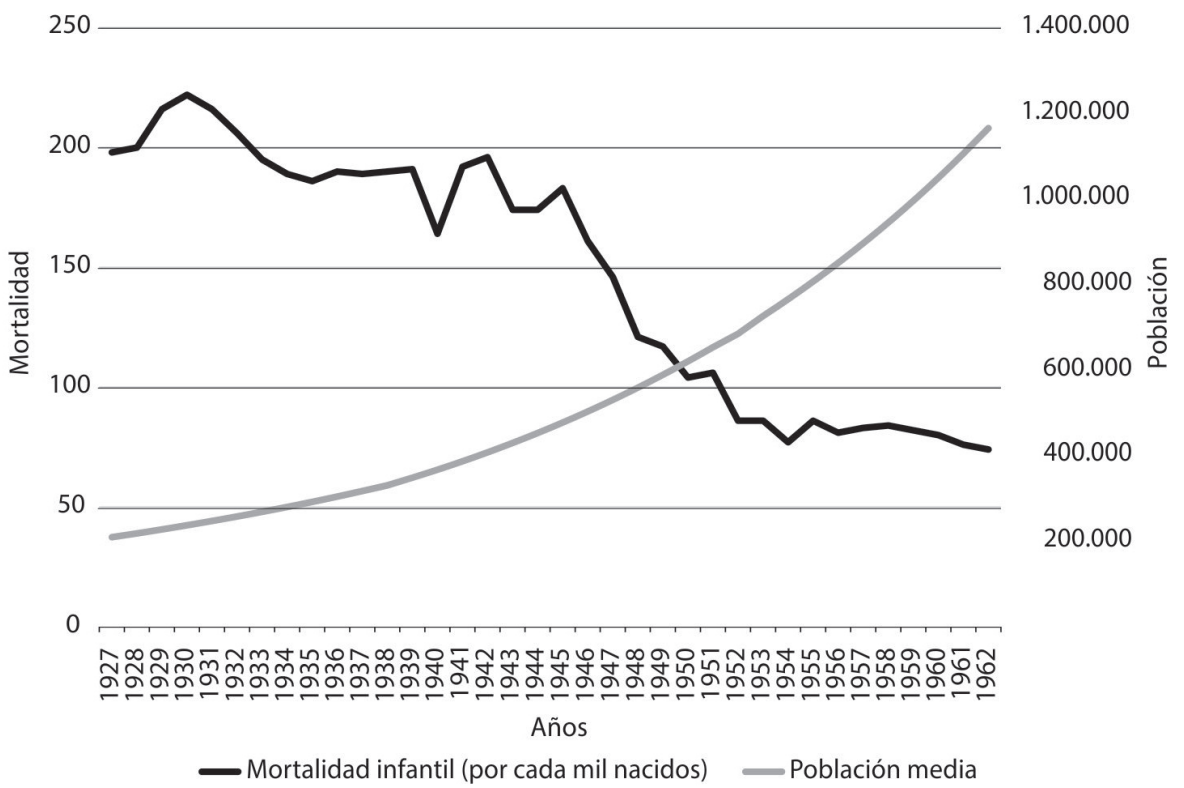

Figura 1: Gráfico de la relación entre población y mortalidad infantil en Bogotá, 1927-1962 [Fuente: Colombia (1952-1965, año 1963, p.35, 78)]

Por otra parte, en 1947 se creó el Instituto Nacional de Nutrición (INN) con la ayuda técnica y financiera del Servicio Cooperativo Interamericano de Salud Pública (SCISP). El SCISP, con presencia en muchos países de América Latina, fue el resultado de un acuerdo bilateral de cooperación técnica en temas de salud entre Colombia y EEUU, iniciado en 1943 y que duraría hasta principios de la década de 1960 (Pohl-Valero et al., 2021). Su contexto de creación y desarrollo se relacionaba con las políticas del Buen Vecino desarrolladas por EEUU antes y durante la Segunda Guerra Mundial, y con los inicios de la Guerra Fría y los esfuerzos de ese país por fomentar el desarrollo económico de los países del entonces denominado "tercer mundo" y por expandir un mercado global (Cueto, 2008).

Una vez creado el INN, tanto éste como el SCISP colaboraron de cerca con la Dirección Municipal de Higiene de Bogotá, que también en 1947 había sido transformada. Uno de sus cambios consistió en la creación de un nuevo Departamento de Higiene, Salubridad y Aseo. Este ente técnico se dividió en seis secciones para gestionar los problemas de salud pública de la ciudad: I. Protección Social y Educación Sanitaria; II. Epidemiología y Bioestadística; III. Protección Materna e Infantil; IV. Nutrición y Alimento; V. Saneamiento; y VI. Laboratorios. La sección IV de nutrición contó con el apoyo del SCISP y del INN y le prestó especial atención a la leche. Además de asumir los exámenes químicos y bacteriológicos del producto, vigilar la salud de las personas involucradas en la cadena lechera y la salubridad 
del trasporte, así como inspeccionar los hatos y el estado de salud del ganado lechero, esta sección se ocupó de orientar nutricionalmente los programas de asistencia alimentaria que había en la ciudad y que en algunos casos distribuían leche de vaca - como los ya mencionados jardines infantiles, salas cuna y gotas de leche (Acuerdo..., 1946).

En todo caso, y de forma similar al gremio de pediatras, los nutricionistas del INN empezaron a señalar que frente a la urgencia de disminuir las tasas de mortalidad infantil y al hecho de que la disponibilidad de leche era muy inferior a la que indicaban los estándares nutricionales, la solución a corto plazo era importar leche descremada en polvo y que el gobierno eliminara los aranceles de este producto (Camacho Gamba, 1953; Góngora López, 1953). A pesar de que algunos agrónomos e higienistas insistían en que "después de la purificación del agua, la pasteurización de la leche es la más importante medida preventiva en el campo de la sanidad" y abogaban por centralizar y hacer obligatoria la pasteurización en Bogotá (Molano Campuzano, 1953b, p.26), a los ojos de estos expertos la efectividad de esta medida era cuestionada - entre otras razones por su difícil y larga implementación.

Y en efecto, una iniciativa oficial de 1946 por centralizar y municipalizar las leches que entraban a Bogotá y, de forma indirecta, por hacer obligatoria la pasteurización fue imposible de realizar. Según algunos salubristas y agrónomos, en buena medida este fracaso se debió a la falta de coordinación entre las instituciones involucradas y a la incapacidad de la cadena de suministro para cumplir las normativas exigidas (Cavelier, 1947; Steiner, 1950). Sea como fuere, en los siguientes años la cantidad de leche cruda vendida en la ciudad continuó siendo superior a la de leche pasteurizada (ver próxima sección). Y aunque la legislación estipulaba que el precio del producto debía aumentar de acuerdo con su grado de calidad, lo cierto es que en los expendios la leche cruda de "excelente calidad" se pagaba al mismo precio que las "sucias" (Gómez, 1949, p.204).

En teoría, la sección IV de la Dirección de Higiene siguió encargada de vigilar que las leches (crudas y pasteurizadas) tuvieran las calidades estipuladas. En 1950 esta sección contaba con uno bromatólogo, tres veterinarios, uno jefe de la Sub-Sección de Leches y 12 inspectores, aunque, un par de años después, uno de sus veterinarios se quejaba nuevamente de la falta de personal y de su muy mala capacitación para controlar hatos, pasteurizadoras y expendios (Decreto..., 1950; Turriago Romero, 1955, p.362-365). Bajo estas condiciones, durante la década de 1950 y en el marco de una nueva clasificación los análisis de las leches crudas y pasteurizadas siguieron indicando su pésima calidad.

Con la colaboración del SCISP y el INN, el Ministerio de Salud Pública elaboró un nuevo código sanitario nacional en 1953. En ese documento, las leches crudas y pasteurizadas eran ahora clasificadas en tres "grados" (A, B, C). Las características fisicoquímicas que debían cumplir todas estas leches parecían haber tenido en cuenta las observaciones de Castro de la década anterior, en tanto que habían reducido el mínimo de extracto desengrasado a 8,50\% y elevado el mínimo de grasa a 3,25\%. En cuanto al grado de contaminación, según el número de bacterias presentes, la leche cruda grado A era la única que se podía consumir así. La cruda B debía ser pasteurizada y la C solo servía para usos industriales. Las pasteurizadas grado A y B debían ser elaboradas a partir de las crudas A y B, respectivamente; y la pasteurizada grado $\mathrm{C}$ era la que violaba los requisitos anteriores y no podía emplearse para el consumo (Colombia, 1953, p.135 y s.). Como en 
la década anterior, la mayoría de las leches analizadas en expendios y pasteurizadoras apenas clasificaban en el grado C, es decir, impropias para el consumo humano (Cedeño Saavedra, 1959, p.134, 150, 168). Así como a principios del siglo XX, la gente seguía en la década de 1950 con la "buena costumbre" de hervirlas (Rojas, Ibáñez, 1919, p. 53; Cedeño Saavedra, 1959, p.228).

\section{Leches materiales: cadena de suministro e infraestructura material}

Toda esta intrincada legislación, clasificación y vigilancia de las calidades de la leche perecía ser absolutamente irrelevante para la mayoría de los actores del sistema lechero y, sobre todo, para las bacterias que se multiplicaban dichosas antes de perecer en las ollas y fogones de los bogotanos. Para las autoridades sanitarias de la ciudad era imposible vigilar una creciente cadena de suministro de un producto que simplemente no lograba cumplir con los requerimientos de calidad establecidos. Las leches en el papel, con sus ideales de civilización y calidad, y las que efectivamente consumían los bogotanos parecían pertenecer a dos mundos distintos. No obstante, esto no quiere decir que el mundo de la legislación no influyera, por lo menos parcialmente, en el mundo de la infraestructura material del sistema lechero. Lo curioso es que la influencia inversa, es decir que las normativas se elaboraran a partir de las condiciones y posibilidades reales, pereció ser mucho menos relevante para varias de las autoridades y expertos involucrados - ya fuera por ideales higiénicos o por intereses económicos.

\section{Características de la cadena de suministro}

En 1934, en la misma época en que se elaboró la mencionada normativa nacional sobre la calidad de la leche, el pediatra Jorge Camacho Gamba (1934, p.110) daba cuenta de algunas de las características de la cadena de suministro en la ciudad:

A Bogotá llegan en carros, camiones, y ferrocarriles leches de toda procedencia y hasta de una distancia de $120 \mathrm{~km}$. Su múltiple origen, nos impide dar datos exactos sobre la manera de su obtención, pero es evidente, por lo que hemos podido apreciar personalmente en algunos de esos ordeños, que en la gran mayoría sus condiciones dejan mucho que desear; es desconocida entre nosotros la necesarísima práctica de recipientes frigoríficos para trasladar la leche de un lugar a otro, sobre todo cuando entre éstos median horas de camino.

Para ese momento, se calculaba que existían unos "280 hatos, con 15.000 vacas poco más o menos, que suministraban alrededor de 70.000 botellas diarias" a la ciudad (Gómez Rueda, 1932, p.491). Una década después la cantidad de hatos en la Sabana de Bogotá apenas había aumentado a 300, aunque el suministro se había casi duplicado. De las 133.330 botellas diarias que entraban a la ciudad en 1943, el 75\% se destinaba al consumo en su "estado original" y el resto a la fabricación de subproductos (Castro, 1944, p.114). Aunque estas cifras eran aproximaciones muy generales, el aumento en el suministro frente al poco incremento de hatos se podría explicar, en principio, por una mayor concentración de vacas por hato y mejoras en su capacidad productiva. Se estimaba que la eficiencia lechera 
de las vacas había aumentado en un 33\% entre las décadas de 1930 y principios de 1950: de un promedio de cinco botellas de leche por vaca por día se había pasado a uno de 6,7 botellas (Bernal, 1932, p.20-21; Cepal, 1957, p.160). ${ }^{2}$ Seguramente esta mayor productividad se debía a los esfuerzos por mejorar las razas lecheras (utilizado toros sementales de razas puras Holstein, Normando y Red-Polled), la introducción de pastos extranjeros (además del extendido Kikuyo, se vendían diferentes tipos de Rye Grass, Carretón y otros), y el suministro de concentrados (en especial afrecho de cebada que era producido por la industria cervecera de la ciudad). En todo caso, la eficiencia lechera de las vacas locales era muy baja en comparación con la de otros países de América Latina (Román, 1946; Abadía Rueda, 1960).

Es posible pensar que el número de hatos mencionados en las décadas de 1930 y 1940 fuera incorrecto, lo cual podría explicar - en parte - el marcado aumento que indicaban las cifras de la década de 1950, además, claro está, del incremento de la demanda por el crecimiento demográfico de la ciudad. Si en 1953 la Cepal calculaba que de las 140 mil hectáreas de la Sabana de Bogotá, el 70\% estaba dedicado a la ganadería de leche (con un promedio de 50 mil vacas ordeñadas diariamente), al final de esa misma década se estimaba que había 2.692 hatos y 65 mil vacas (lo que indicaba un promedio de 7,7 botellas por vaca por día) que suministraban diariamente medio millón de botellas de leche a Bogotá - incluyendo los hatos de la Sabana, el resto de Cundinamarca y algunas zonas de Boyacá (Cepal, 1957, p.160; Cedeño Saavedra, 1959, p.93; Jones, Ashton, 1961, p.4). De esas 500 mil botellas de leche, el 50\% iba a pasteurizadoras, el 32\% a expendios de leche cruda, el 7\% a la industria de productos lácteos (queso, mantequilla, helados) y un porcentaje similar correspondía a la entrega directa de leche a domicilio. El resto (cerca de 4\%) estaba destinado a instituciones de asistencia alimentaria y al manejo por parte de otros intermediarios (Cedeño Saavedra, 1959, p.92).

Con respecto a las pasteurizadoras de la ciudad, entre las décadas de 1930 y 1950 su número se había mantenido casi igual, aunque su capacidad de producción había aumentado. De las dos pasteurizadoras mencionadas en 1930, se había pasado a tres en 1940 (San Luis, Central de Leches y Bogotá) y dos más instaladas en haciendas lecheras (Camacho Gamba, 1934, p.111; Castro, 1944, p.120). Además de la breve existencia de Icodel (Industria Colombiana de Leches S.A.), una empresa altamente tecnificada que inició labores en 1944 para la pasteurización y producción de leche en polvo pero que quebró en 1947, en la década de 1950 se reportaban tres pasteurizadoras en la ciudad - San Luis, Bogotá y Santa Fe - y cinco en municipios aledaños - Colesal, Algarra, Rodeo, Chucuita y Trébol (Cavelier, 1947; Cedeño Saavedra, 1959, p.141). Para ese momento, la pasteurizadora Bogotá era la más antigua (creada en 1933), y San Luis era la más grande y de mejor calidad. En 1955 se indicaba que esta última tenía casi 200 trabajadores y 35 camiones para repartir su leche pasteurizada. La calidad de la leche que recibían en cantinas era analizada en su propio laboratorio, y la aceptada era almacenada en tanques para luego iniciar el proceso de pasteurización (La deficiente..., 17 feb. 1955, p.10). En 1958, San Luis tenía una capacidad instalada para producir $250 \mathrm{mil}$ botellas diarias, aunque solo pasteurizaba $127 \mathrm{mil}$. El resto de pasteurizadoras no superaban una capacidad de 50 mil botellas diarias, y su producción real era inferior a las 13 mil (Cedeño Saavedra, 1959, p.141). 
Así, la venta de leche pasteurizada se inició en la década de 1930 y empezó a competir con el expendio de leche cruda, aunque solo a partir de la segunda mitad de la década de 1950 el consumo de leche pasteurizada superó al de la cruda (Colombia, 1952-1965, año 1955, p.144, año 1959, p.155). Según las estadísticas municipales, el número de expendios de leche cruda registrados en la ciudad había creció de 256 en 1939 a 568 en 1954, siendo la zona 1 de la ciudad - uno de los sectores más pobres y ubicado en el suroccidente - la que había registrado un mayor crecimiento de expendios (de nueve en 1939 a 107 en 1954) (Bogotá, 1940-1951, año 1940, p.79; Colombia, 1952-1965, año 1954, p.144). Aunque el Anuario municipal de estadísticas (luego llamado Anuario estadístico de Bogotá D.E.) dejó de registrar las estadísticas del número de expendios en 1954, el veterinario Cedeño Saavedra indicaba que al año siguiente habían aumentado a 629, pero luego, en 1958, habían bajado a 500 (Cedeño Saavedra, 1959, p.122). Lo cual podría ser un efecto del paulatino desplazamiento en el mercado de leches crudas a pasteurizadas.

En todo caso, el consumo de leches en las décadas de 1940 y 1950 se mantuvo muy por debajo de las recomendaciones nutricionales. Hasta 1954 las estadísticas indicaban que en promedio la población bogotana no tomaba más que un pequeño vaso de leche al día (entre $100 \mathrm{~cm}^{3}$ y $135 \mathrm{~cm}^{3}$ ) (ver Figura 2). Estas estadísticas solo registraban la venta de leche cruda, con lo que el consumo real podría ser un poco mayor. Luego de un par de años sin registros (1956-1958), en 1959 se empezó a incluir también la venta de leche pasteurizada, lo que efectivamente reflejó un aumento en el consumo a casi $230 \mathrm{~cm}^{3}$ (ver Figura 3). Algo todavía muy lejano a los $500 \mathrm{~cm}^{3}$ para adultos y a los $1.000 \mathrm{~cm}^{3}$ para niños y embarazadas que el INN recomendaba (Góngora López, 1953, p.215).

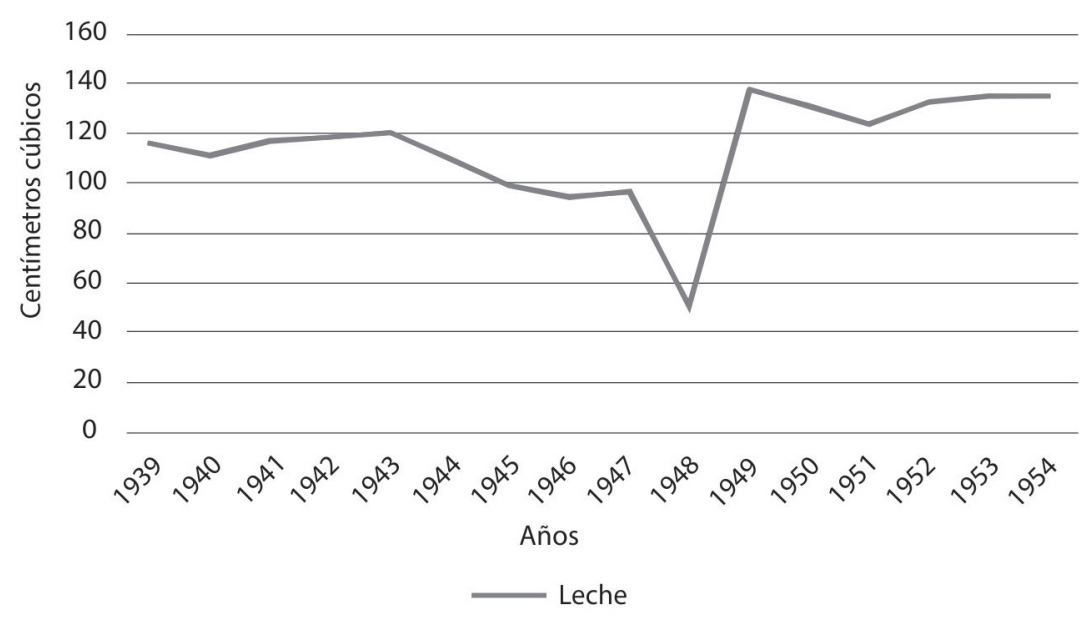

Figura 2: Gráfico del consumo promedio diario de leche cruda por persona en Bogotá, 19391954 [Fuente: Bogotá (1940-1951); Colombia (1952-1954)] 


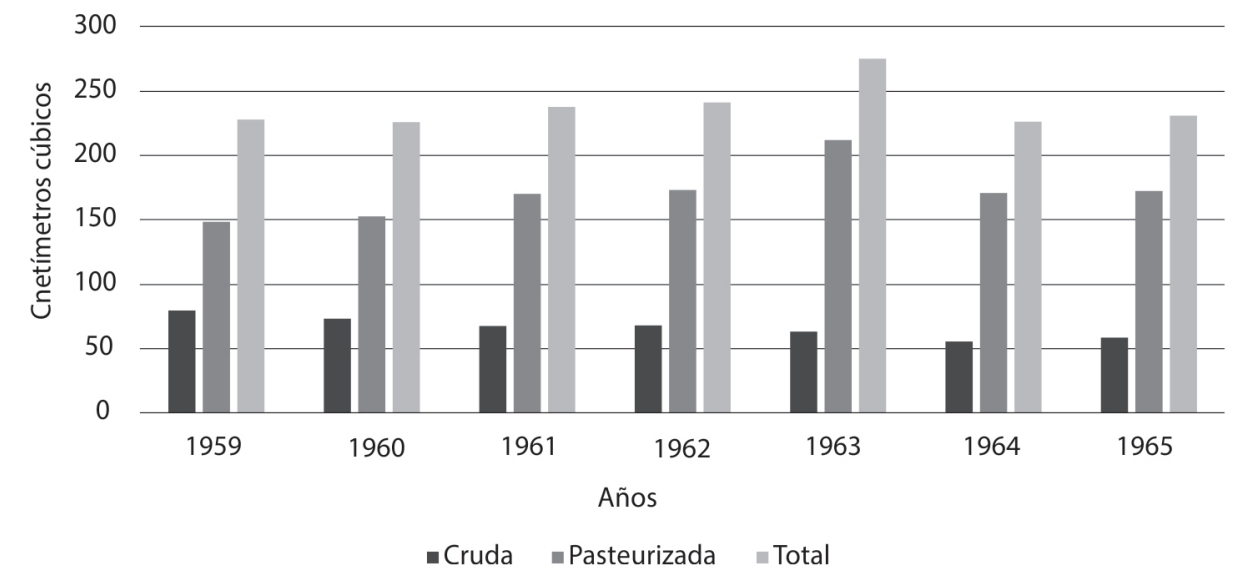

Figura 3: Gráfico del consumo promedio diario de leche cruda y pasteurizada por persona en Bogotá, 1959-1965 [Fuente: Colombia (1952-1965, años 1959 a 1965)]

\section{Normativas, infraestructura y circuitos comerciales}

A pesar del bajo consumo en la ciudad y de la persistencia de las bacterias en todos los eslabones de la cadena de suministro de leche - hatos, transportistas, pasteurizadoras y expendios -, cada uno de estos eslabones intentaba adaptarse, hasta cierto punto, a las normativas nacionales y municipales sobre la calidad de la leche. En el extremo de la cadena de producción se había estructurado un amplio circuito comercial que intentaba suplir los requerimientos exigidos para producir leche de buena calidad. ${ }^{3}$ En la década de 1940, por ejemplo, se había creado en Bogotá una Asociación de Productores de Leche, la cual era una "entidad formada para defender los intereses de esta valiosa industria" (Anuncio..., 1945, p.66). En su publicidad, la Asociación ofrecía "cantinas, enfriadoras, baldes, filtros, máquinas para ordeñar y semillas de pasto y abonos" a precio de costo a sus asociados (Anuncio..., 1946, p.49). Varios de estos insumos estaban destinados, más que a aumentar la productividad, a cumplir con las normativas vigentes. Por ejemplo, los baldes intentaban reemplazar la vieja costumbre de utilizar vasijas de madera en el ordeño, las cuales habían sido prohibidas por la legislación lechera. El ordeño mecánico, aunque pensado para optimizar este proceso, también se concebía como una forma de superar la pésima higiene de los ordeñadores y su costumbre de escupirse en las manos antes de empezar a exprimir las ubres de las vacas (Publicidad..., 1946; Turriago Romero, 1955, p.372). Importancia central tenían las enfriadoras (por lo general de cortina sencilla), ya que la legislación había sido cada vez más exigente con la temperatura mínima que debía tener la leche desde su ordeño hasta el momento de su transporte a la ciudad. Esto era especialmente crítico para los hatos que hacían dos ordeños al día, en la medida que la leche obtenida por el de la tarde tenía que esperar, por lo general, hasta el siguiente día para ser enviada a la ciudad. 
Pero este entramado tecnológico y comercial en favor de la calidad de la leche solo era económicamente realizable y/o deseable para unos pocos hatos y en algunos casos requería de una infraestructura inexistente. Por ejemplo, el ordeño mecánico era difícil de implementar por la "la falta de electrificación rural" (Gómez, 1949, p.195) y disponibilidad de repuestos. A la vez que dado los muy bajos salarios de los campesinos, el costo de producir leche con estos equipos se elevaba ostensiblemente frente al ordeño manual. A finales de la década de 1940 se señalaba que el director municipal de higiene había hecho un gran esfuerzo por facilitar a los productores la "importación e instalación de equipos de refrigeración" (González, 1952, p.10). No obstante, a finales de la década de 1950, solo el 11\% de los hatos tenía cortinas para enfriamiento y el 3,3\% poseía ordeño mecánico. De hecho, un escaso 13\% contaba con establos para el ordeño y, en general, apenas un 3,5\% de los hatos de la época (92 de 2692) poseían todos los equipos necesarios para la "obtención, filtración, enfriamiento, conservación y esterilización" que las normativas exigían para la producción de leche de calidad A y B (Cedeño Saavedra, 1959, p.10-11, 20, 50, 94).

Los hatos más pequeños (la mitad de todos los existentes producía menos de 50 botellas de leche al día) no tenían la capacidad económica para adquirir la mayoría de estos equipos. Además, bastantes de ellos eran de productores que arrendaban potreros para tener a sus vacas (un 12,7\% del total de los hatos). No obstante, muchas de las haciendas con una producción mayor a 200 botellas tampoco cumplían con la infraestructura esperada (Cedeño Saavedra, 1959, p.93-97). En buena medida, esto se debía a que en el mercado se terminaba pagando al mismo precio la leche de buena calidad que la de mala calidad, con lo cual eran muy pocos los productores lecheros, aun los que contaban con capacidad económica, que se disponían o percibían un aliciente económico en tecnificar sus hatos (Gómez, 1949, p.204). No era de sorprender entonces que el economista canadiense Lauchlin Currie, quién había llegado a Colombia en 1949 como líder de una misión del Banco Mundial para realizar un plan de desarrollo económico para el país, se hubiera quebrado en su intento por montar un hato lechero en la Sabana de Bogotá. En efecto, con la llegada de Rojas Pinilla al poder en 1953, Currie dejó de asesorar al gobierno en temas económicos y se dedicó a la industria lechera, logrando tener un hato altamente tecnificado y de vacas Holstein de altísimo rendimiento. Pero tuvo que abandonar su empresa por falta de rentabilidad (Sandilands, 2003, p.6; Flórez-Malagón, 2008, p.119).

Ya fuera por incapacidad económica o por falta de un aliciente monetario, lo cierto es que el almacenamiento y transporte de leche, en la mayoría de los casos, no cumplía, con las crecientes exigencias sobre la temperatura mínima con la que se debía mantener el producto desde el ordeño hasta su entrada a Bogotá (Decreto..., 1948). Frente a esta situación, paulatinamente se había ido generando un eslabón adicional en la cadena de suministro. Se trataba de las plantas de enfriamiento. A finales de la década de 1950 existían unas treinta de estas plantas en zonas rurales y en Bogotá. Por lo general, los productores pequeños sacaban por la mañana su leche en cantinas y otros envases (ollas, tarros, botijas etc.) a la vera del camino donde era recogida por los camiones de estas plantas. En estos lugares se enfriaba el producto con cortinas de agua y gas y luego lo enviaban a los expendios de leche cruda y a algunas pasteurizadoras. Pero parecía que este enfriamiento no cumplía su función, dado el largo tiempo que pasaba entre la recolección y el inicio del enfriado, así 
como por la falta de esterilización de los equipos de las plantas. La organización comercial de este eslabón parecía ser "más que todo especulativa y nunca con el ánimo de servir al [pequeño] productor... quien se ve obligado a vender la leche a tales plantas a precios bajos, sin obtener un verdadero beneficio" (Cedeño Saavedra, 1959, p.79, 104-111).

En torno a los eslabones de la pasteurización y el expendio, también se gestó un mercado de insumos bastante amplio. En el caso de las plantas pasteurizadoras la mayoría de sus equipos eran importados, lo cual no dejaba de interesar a empresarios y autoridades extranjeras. Por ejemplo, el ya mencionado veterinario Jaime Castro fue enviado por la dirección municipal de higiene, en su calidad de jefe del laboratorio de leche de la ciudad, a EEUU en 1946 para asistir a una exposición de industrias lácteas. Además de asistir a la exposición y de visitar varias pasteurizadoras en diferentes ciudades, Castro fue invitado por el Departamento de Agricultura a conocer su sección de industria lechera. Allí se enteró de que la Oficina de Asuntos Interamericanos (misma dependencia que en sus inicios coordinó el SCISP) había auspiciado un detallado estudio sobre la industria lechera en Colombia en 1942 (Castro, 1946). Además de la consabida referencia sobre la importancia de un alto consumo de leche y derivados para el desarrollo y salud del pueblo colombiano (y que su bajo consumo se debía tanto a la poca disponibilidad como al desconocimiento popular de su alto valor nutritivo), el informe indicaba que "existe en Colombia un excelente futuro para el mercado de productos de alta calidad y el cual es fácil de conquistar" (Hodgson, Hunziker, 1942 citado en Castro, 1946, p.696). Para lograr esto, se instaba a las autoridades locales a fomentar y aumentar el consumo de leche pasteurizada de la mejor calidad y evitar que se consumiera leche cruda, así como se reivindicaba la "creación de una organización de carácter nacional que permita aglutinar a los manufactureros y distribuidores de productos lácteos" con el fin de lograr un "desarrollo ordenado de la industria" (Hodgson, Hunziker, 1942 citado en Castro, 1946, p.697). Quizás, esta "conquista" implicaba para los intereses económicos de EEUU una disminución en la cantidad de leche en polvo y derivados lácteos que exportaba al país, pero ciertamente generaba un mercado de insumos tecnológicos interesante.

La fallida trayectoria de la mencionada empresa Icodel es un ejemplo revelador al respecto. Su creación se remontaba a 1941, cuando el Instituto de Fomento Industrial (fundado en 1940, con el fin de promover la creación y ensanche de empresas dedicadas a la explotación de industrias básicas o de interés nacional) aportó más del 50\% del capital necesario (Colombia, 1966, p.92, 95). Aunque su funcionamiento empezó en 1944, ya en 1942 observadores internacionales destacaban que su intención era "producir productos lácteos suficientes para abastecer las necesidades locales y para reemplazar el suministro importado" (Wylie, 1942, p.124). El Departamento de Comercio de los Estados Unidos también destacaba que se trataba de la primera industria lechera realmente moderna en Bogotá, que esperaba acaparar prácticamente la totalidad de la leche producida en la Sabana de Bogotá (con una capacidad de producción diaria de 35 mil botellas de leche pasteurizada, y expandible a 100 mil botellas, y de 2 mil libras de leche en polvo) y que todo su equipo de pasteurización, refrigeración, secadoras, evaporadoras y esterilizadoras había sido comprado en EEUU (Dairy..., 1944, p.23). En este sentido, Icodel representó uno de los fallidos intentos del gobierno colombiano de la época por fomentar la industrialización y 
estimular la autonomía alimentaria, a la vez que reflejó los intereses comerciales detrás de la cooperación técnica estadounidense en temas de salud y nutrición.

En conexión con lo anterior, la cadena de distribución de leche pasteurizada implicaba, por lo menos en teoría, que los camiones repartidores, los expendios y las casas de los consumidores tuvieran equipos de refrigeración y/o neveras, los cuales también eran importados. Como mencionaba la publicidad de General Electric a principios de la década de 1950, la "electrificación" era un "símbolo del progreso" y sus equipos industriales y domésticos de refrigeración "conservan la frescura de los alimentos" y "protegen la salud de la familia" (Publicidad..., 20 ago. 1952, p.15). Pero en la práctica, tanto los camiones de reparto (que transportaban la leche en botellas de vidrio), como la mayoría de los expendios y casas de los consumidores carecían de los equipos de refrigeración para que realmente funcionara esta cadena de suministro (Turriago Romero, 1955, p.364).

El circuito de la leche cruda, por el contrario, se correspondía mejor con las condiciones materiales del momento. Ciertamente, los expendios de este tipo de leche requerían de una infraestructura tecnológica menos compleja y, junto con los pequeños productores, eran los eslabones más débiles y poco intervenidos de la cadena. En general, los expendios eran manejados por personas humildes que arrendaban un pequeño local y se les exigía tener un permiso de funcionamiento y poseer un carnet de sanidad. Las características de higiene de los locales eran poco vigiladas por las autoridades, a pesar de - o más bien debido a - que existían cientos de ellos en la ciudad. La leche la recibían directamente de los hatos, muchos de ellos sin el permiso sanitario correspondiente, o de las plantas de enfriamiento. En el local almacenaban la leche en tanques y los compradores la adquirían trayendo sus propios envases. Varios de los expendios también repartían su producto a domicilio en vasijas (Turriago Romero, 1955, p.360-361). Aunque la calidad del producto recibido y vendido era muy mala, muchos consumidores la preferían a la pasteurizada por su sabor, menor precio y la hervían, lo cual permitía un mayor tiempo de vida antes de dañarse en comparación con la pasteurizada no refrigerada (Paredes Chaves, 1954, p.12-19; Turriago Romero, 1955, p.364). El clima de Bogotá, con una temperatura media cercana a los $14^{\circ} \mathrm{C}$ y mínima por debajo de los $6^{\circ} \mathrm{C}$ (Colombia, 1952-1965, año 1954, p.26), era una condición atmosférica que también favorecía un sistema de suministro que no necesariamente necesitaba una infraestructura de refrigeración para mantener la frescura de los alimentos, por lo menos por cierto tiempo.

Además de las cuestiones climáticas, económicas y de infraestructura que auspiciaban el circuito de la leche cruda, a finales de la década de 1940, y durante un corto periodo, se fomentó oficialmente su consumo, lo cual fue duramente criticado por las pasteurizadoras (González, 1952, p.13). Posiblemente esto tuvo que ver con la pésima calidad de la leche que vendían la mayoría de las pasteurizadoras de ese momento. Incluso, el Concejo de Bogotá le solicitó en 1949 al alcalde que advirtiera públicamente que la leche pasteurizada "de ninguna manera, por ahora, ... pued[e] ser consumida sin hervirla previamente" (Proposiciones..., 1949, p.80).

También se intentó regular de mejor manera los expendios de leche cruda. En 1948, las autoridades municipales estipularon que los locales debían tener suministro de agua, tanques metálicos inoxidables, lavamanos, paredes de baldosín, personal con uniformes 
blancos, una baranda que separara al vendedor del comprador, caja registradora era manejada por una persona diferente, y un cartel que indicara "la calidad y precio de la leche" (Resolución..., 1948, p.16). Como en otros eslabones de la cadena de suministro, estas normativas no supusieron una mejora en la calidad de la leche, pero sí generaron ciertas trasformaciones de infraestructura.

En efecto, en la década de 1950 los expendedores habían hecho un esfuerzo por adaptarse a la nueva normativa, aunque varias de las disposiciones no se cumplían o eran imposibles de lograr. Por ejemplo, algunos barrios de la ciudad no contaban con alcantarillado y servicio de agua potable y, en consecuencia, los expendios en estos barrios no tenían los servicios indispensables para cumplir con lo exigido (Cedeño Saavedra, 1959, p.122). El uso de los tanques especiales sí se había adoptado de forma generalizada, aunque aparentemente eran operados inadecuadamente. Se mencionaba que no se utilizaba el agitador, con lo cual "en la parte superior del tanque se acumula la grasa, que es utilizada para otros fines domésticos personales del expendedor" (Turriago Romero, 1955, p.361).

Como fuera, lo cierto es que se había creado una interesante demanda de tanques inoxidables en un mercado que, en muchos casos, seguía prefiriendo la leche cruda a la pasteurizada y cuya principal y realmente efectiva estrategia de higienización requería de una infraestructura al alcance de casi todos: una olleta y un fogón. En todo caso, la legislación lechera, estructurada en el cruce de diversos intereses y formas de entender el problema, persistió la mayoría de las veces en un ideal de calidad y un imaginario de infraestructura tecnológica que en la práctica generó la ya mencionada "anarquía" del sistema, el cual le ofreció al consumidor final un producto encarecido por el aumento de eslabones en la cadena de suministro y, en realidad, poco demandado por los bogotanos y escasamente fomentado por las autoridades.

\section{Consideraciones finales}

Durante el periodo estudiado en este artículo no existió una política clara de fomento al consumo de leche de vaca. A los ojos de las autoridades sanitarias pareció prevalecer el significado de "veneno blanco" sobre el de "alimento perfecto", lo que presumiblemente impidió, por lo menos parcialmente, el despliegue de campañas publicitarias extendidas sobre la importancia de tomar leche, la creación de milkbars en la ciudad o la implementación de programas de provisión pública de leche a escolares y familias, como ocurrió en Uruguay, Brasil o Chile (Birn, 2008; Brinkmann, 2021; Goldsmith Weil, 2017). Más allá de pequeños programas de entrega de leche gratuita en gotas de leche y salas cunas a hijos de tuberculosos y a infantes pobres, el incremento de la leche que llegaba a Bogotá se debió a su crecimiento demográfico y no a un aumento en el consumo promedio. Y el descenso en la mortalidad infantil que empezó a ocurrir en la ciudad a partir de 1945, nunca fue relacionado por los higienistas y autoridades sanitarias con la leche. Por el contrario, en la década de 1950 prevaleció el argumento de que la principal razón para higienizar la leche era disminuir la mortalidad infantil.

Esta situación se relacionó con el aducido estado de "anarquía" existente entre productores, distribuidores, expendedores y autoridades. Como hemos visto, para algunos 
ganaderos, el grave problema del sistema lechero se debía especialmente a las malas gestiones de la dirección municipal de higiene. Pero para otros expertos, las causas eran más complejas. Por ejemplo, en 1950 el agrónomo y experto en la industria láctea Jorge Steiner entendía que el fracaso de las campañas de higienización de la leche se debía a "una especie de barrera infranqueable que consiste en la falta de coordinación existente entre las diversas entidades encargadas de fomentar y controlar la industria lechera" (Steiner, 1950, p.43). Entre ellas se encontraban los Ministerios de Agricultura, Salud, y Comercio, la Dirección Municipal de Higiene y la Oficina Nacional de Precios; cada una representando intereses y fomentando estrategias en ocasiones contrapuestas. Además, señalaba que los códigos lecheros locales eran burdas copias de los "vigentes en Estados Unidos" (Steiner, 1950, p.44), asumiendo un estado de industrialización y tecnificación que apenas empezaba a gestarse en Bogotá y su sabana. Desde su experiencia, Steiner destacaba que las disposiciones oficiales se elaboraban sin contemplar estudios serios sobre la realidad local de la industria lechera, con lo que las normativas eran imposibles de cumplir y generaban una gran confusión. En gran medida, esto se debía a la falta de atención que las autoridades y legisladores les prestaban a los expertos locales: "Siempre se consultan técnicos extranjeros completamente ajenos a nuestro medio, quienes vienen a Colombia a pasar una temporada de uno o dos meses y luego rinden su informe, en lugar de consultar a profesionales colombianos" (Steiner, 1950, p.45).

Steiner señalaba como ejemplo de esto la decisión de la Dirección Municipal de Higiene de basarse en los estudios de un experto enviado a Colombia en 1950 por el SCISP para elaborar una nueva reglamentación y clasificación de la leche, en el marco de un intento fallido de crear una federación de productores de leche que manejara toda la cadena de suministro y de aumentar los precios de la leche de acuerdo con su calidad. Por su parte, el pasteurizador González también mencionaba que "las misiones americanas venidas al país especialmente contratadas para el estudio del problema" (como el SCISP y Unicef) hacían sugerencias y recomendaciones "nada distinto a lo que nosotros ya sabemos" (González, 1952, p.20). Además, las soluciones propuestas no eran llevadas a la práctica y el camino a seguir era "traer otras misiones y consultar más y más" (p.21). Y en efecto, el nuevo código sanitario de leches que finalmente se estableció en 1953 fue un producto del SCISP, con una clasificación y exigencias tan complejas que una década después se decretó una nueva normativa para Bogotá con el objetivo explícito de "actualizar la legislación sobre leche" y de "simplificarse los controles para hacerlos más efectivos" (Decreto..., 1963, p.1).

En resumen, el esquema de mejoramiento del sistema lechero acá estudiado se caracterizó por una arquitectura institucional desarticulada entre los diversos organismos involucrados, por una legislación inoperante y alejada de las posibilidades locales y por una serie de tensiones entre expertos y autoridades sobre cómo lograr la higienización de la leche. En la práctica, el ensamblaje del sistema siguió un camino que se caracterizó por la pequeña producción, escasa tecnificación, diversidad de intermediarios, predominio de leches crudas, costumbre de hervirlas (también las pasteurizadas) y bajos consumos. Esto parecía ser el opuesto del tipo de industria lechera que quería conquistar el mercado de insumos tecnológicos de EEUU en el país. Es evidente que, a través de diversos organismos de cooperación técnica, EEUU buscó incidir en una reglamentación y clasificación de la 
leche orientada a la industrialización, pasteurización y refrigeración, con un claro interés económico en ello. En buena medida, todo este tinglado institucional, normativo y comercial fracasó, lo que no quiere decir que el sistema lechero y su infraestructura no se vieran afectados por un ideal de progreso, civilización y salud que se construyó en torno a la leche de buena calidad.

Quizás, una ama de casa resumía de la mejor forma posible la trayectoria que había recorrido la leche en Bogotá durante la primera mitad del siglo XX: "En mis tiempos... la botella de leche - en cantina y sin agua - costaba 2 centavos, hoy pasterizada, homogenizada, oxigenada, enfriada, etc. cuesta 60 centavos y ya no sabe lo mismo" (Qué opinan..., 16 feb. 1955, p.3).

\section{NOTAS}

${ }^{1}$ El libro de Álvarez Múnera, quizás la única excepción, explora, desde la historia empresarial ganadera, diversos aspectos de la producción y consumo de leche en el departamento de Antioquia entre 1920 y 1960.

${ }^{2}$ Estos promedios se referían a las vacas de la Sabana de Bogotá en 1932 y 1953. Según los datos de la Cepal, las vacas del Valle de Ubaté, una región 100km al nororiente de Bogotá, tenían, en 1953, un promedio de producción de siete litros por día, aunque algunos hatos lograban llegar hasta 15 litros. El 65\% de la producción lechera de esta región (60 mil litros diarios) se destinaba al mercado de Bogotá.

${ }^{3}$ Evidentemente, estas cuestiones también se relacionaron con las políticas de fomento agrícola de la época. No obstante, un análisis al respecto cae fuera de los alcances del presente artículo.

\section{REFERENCIAS}

ABADÍA RUEDA, Daniel. Producción lechera y alimentos concentrados. Revista de la Facultad de Medicina Veterinaria, v.23, n.120, p.647-671, 1960.

ACUERDO número 78 de 1946. Registro Municipal, v.67, n.330-336, p.556-565, 1946.

AGUILAR-RODRÍGUEZ, Sandra. Nutrition and modernity: milk consumption in 1940s and 1950s Mexico. Radical History Review, n.110, p.36-58, 2011.

ÁLVAREZ MÚNERA, José Roberto. Mercado, ganado y territorio: haciendas y hacendados en el Oriente y el Magdalena Medio antioqueños (19201960). Medellín: Editorial de la Universidad de Antioquia, 2016.

ANUNCIO de la Asociación de Productores de Leche. Agricultura Tropical, v.2, n.7, p.49, 1946.

ANUNCIO de la Asociación de Productores de Leche. Agricultura Tropical, v.1, n.9, p.66, 1945.

ARCHIVO del Ayuntamiento. Registro Municipal, v.59, n.165-168, p.506-507, 1939.

ATKINS, Peter. The material histories of food quality and composition. Endeavour, v.35, n.2-3, p.74-79, 2011.
ATKINS, Peter. Liquid materialities: a history of milk, science and the law. Farnham: Ashgate, 2010.

BEJARANO, Jorge. Alimentación y nutrición en Colombia. Bogotá: Editorial Cromos, 1941.

BELTRÁN, Gregorio. Economía de producción agrícola en Colombia. Revista Facultad Nacional de Agronomía, v.13, n.43, p.1-191, 1953.

BERNAL, Washington. Apuntaciones sobre producción de leche. Bogotá: Imprenta del Departamento, 1932.

BIRN, Anne-Emanuelle. Doctors on record: Uruguay's infant mortality stagnation and its remedies, 1895-1945. Bulletin of the History of Medicine, v.82, n.2, p.311-354, 2008.

BOGOTÁ. Contraloría Municipal. Anuario Municipal de Estadística. Bogotá: [s.n.], [19401951].

BRINKMANN, Sören. Un matrimonio malogrado: políticas de alimentación y agricultura en la "era Vargas" (1930-1945). In: Pohl-Valero, Stefan; Vargas Domínguez, Joel. El hambre de los otros: ciencia y políticas alimentarias en Latinoamérica, siglos XX y XXI. Bogotá: Editorial de la Universidad del Rosario, 2021. 
BRINKMANN, Sören. Leite e modernidade: ideologia e políticas de alimentação na era Vargas. História, Ciências, Saúde - Manguinhos, v.21, n.1, p.263-280, 2014.

BUSCHINI, José. La Tercera Conferencia Internacional de la Alimentación y el problema nutricional en América Latina, 1939. In: PohlValero, Stefan; Vargas Domínguez, Joel. El hambre de los otros: ciencia y políticas alimentarias en Latinoamérica, siglos XX y XXI. Bogotá: Editorial de la Universidad del Rosario, 2021.

BUSCHINI, José. La comercialización de la leche de consumo en la Ciudad de Buenos Aires y su carácter controversial, 1924-1945. Estudios Sociales del Estado, v.4, n.8, p.38-66, 2018.

CAMACHO GAMBA, Jorge. Las necesidades de leche en polvo en Colombia. Revista Colombiana de Pediatría y Puericultura, v.12, n.3, p.212-214, 1953.

CAMACHO GAMBA, Jorge. Apuntaciones sobre química de la alimentación, leche ácida, caseosa y estado nutritivo del lactante en Bogotá. Bogotá: Universidad Nacional de Colombia, 1934.

CASTRO, Jaime. Informe del jefe de laboratorios. Registro Municipal, v.66, n.330-336, p.690-698, 1946.

CASTRO, Jaime. Sobre la necesidad de una revisión a las disposiciones vigentes para leches y derivados. Revista de la Facultad de Medicina Veterinaria, v.13, n.87, p.101-183, 1944.

CAVELIER, Jorge E. Informe del director del Departamento de Higiene, Salubridad y Aseo. Registro Municipal, v.67, n.354-357, p.575-579, 1947.

CEDEÑO SAAVEDRA, Guillermo Hernando. El problema de la leche en Bogotá D. E. Bogotá: [s.n.], 1959.

CEPAL, Comisión Económica para América Latina y el Caribe. Análisis y proyecciones del desarrollo económico III: el desarrollo económico de Colombia. Ciudad de México: Naciones Unidas, 1957.

COLOMBIA. Departamento Administrativo de Planeación. El desarrollo industrial de Colombia. Santiago de Chile: Cepal, 1966.

COLOMBIA. Departamento Administrativo Nacional de Estadística. Anuario estadístico de Bogotá D.E. Bogotá: [s.n.], [1952-1965].

COLOMBIA. Ministerio de Salud Pública. Código sanitario nacional. Bogotá: Imprenta Nacional, 1953.

CUETO, Marcos. International health, the early Cold War and Latin America. Canadian Bulletin of Medical History, v.25, n.1, p.17-41, 2008.
CUEVAS, Francisco. Higienización de las leches en Bogotá. Bogotá: Editorial de Cromos, 1924.

DAIRY products. Foreign Commerce Weekly, v.15, n.6, p.23, 1944.

DECRETO 295 de 1963. Alcaldía Mayor de Bogotá. Complicación de normatividad, doctrina y jurisprudencia. Disponible en: https://www. alcaldiabogota.gov.co/sisjur/normas/Norma1. jsp? $\mathrm{i}=13414 \& \mathrm{dt}=\mathrm{S}$. Accesso en: 8 sep. 2021.

DECRETO número 664 de 1950. Registro Municipal, v.70, n.429-432, p.454-456, 1950.

DECRETO número 272 de 1948. Boletín Informativo. Órgano de la Dirección de Higiene del Municipio de Bogotá, v.2, n.16, p.6-13, 1948.

DUPUIS, E. Metanie. Nature's perfect food: how milk became America's drink. New York: New York University Press, 2002.

EL PROBLEMA de las leches. El Tiempo, p.1, 14, 20 ago. 1952.

FLÓREZ-MALAGÓN, Alberto. Ganado, ¿para qué? Usos del ganado en Colombia, 1900-1950. In: Flórez-Malagón, Alberto. El poder de la carne: historias de ganaderías en la primera mitad del siglo $X X$ en Colombia. Bogotá: Editorial Pontificia Universidad Javeriana, 2008. p.118-163.

GARCÍA, Mónica; POHL-VALERO, Stefan. Styles of knowledge production in Colombia, 18501920. Science in Context, v.29, n.3, p.347-377, 2016.

GOLDSMITH WEIL, Jael. Milk makes state: the extension and implementation of Chile's state milk programs, 1901-1971. Historia, v.50, n.1, p.79-104, 2017.

GÓMEZ, Ramón. Montaje y explotación de una industria lechera. Revista de la Facultad de Medicina Veterinaria, v.18, n.99, p.182-205, 1949.

GÓMEZ RUEDA, Manuel. Presencia del bacilo tuberculoso en las leches que se dan al consumo en Bogotá. Revista de la Facultad de Medicina Veterinaria, v.4, n.35, p.488-492, 1932.

GÓNGORA LÓPEZ, José. El problema de la disponibilidad de leche en Colombia. Revista Colombiana de Pediatría y Puericultura, v.12, n.3, p.215-222, 1953.

GONZÁLEZ, José S. Leche pura y pura leche: estudio presentado por la Pasteurizadora Bogotá, a la Dirección Municipal de Higiene, sobre pasterización de la leche en Bogotá. Bogotá: Editorial Pax, 1952.

JONES, J.B.; ASHTON, E.D. Informe sobre la industria lechera en la zona de Bogotá. Bogotá: Superintendencia de Regulación Económica, 1961. 
KALMANOVITZ, Salomón; LÓPEZ ENCISO, Enrique. La agricultura colombiana en el siglo XX. Bogotá: Fondo de Cultura Económica, 2006.

LA DEFICIENTE producción es la causa directa en el alza de la leche. El Tiempo, p.10, 17 feb. 1955.

MÁRQUEZ VALDERRAMA, Jorge Humberto; GALLO VÉLEZ, Oscar. Eufemismos para el hambre: saber médico, mortalidad infantil y desnutrición en Colombia, 1888-1940. Historia y Sociedad, v.32, p.21-48, 2017.

MOLANO CAMPUZANO, Joaquín. Un símbolo de democracia: leche sana e higiénica. Agricultura Tropical, v.9, n.1, p.47-50, 1953a.

MOLANO CAMPUZANO, Joaquín. Las centrales lecheras. Agricultura Tropical, v.9, n.9, p.25-32. 1953b.

MUÑOZ, Cecilia; PACHÓN, Ximena. Mortalidad infantil, crecimiento demográfico y control de la natalidad: una lucha por la supervivencia de la infancia bogotana (1900-1989). Maguaré, v.6-7, p.101-152, 1988.

NOGUERA, Carlos Ernesto. Medicina y política: discurso médico y prácticas higiénicas durante la primera mitad del siglo XX en Colombia. Medellín: Fondo Editorial Universidad Eafit, 2003.

OSP, Oficina Sanitaria Panamericana. Actas de la décima Conferencia Sanitaria Panamericana. Bogotá: Oficina Sanitaria Panamericana, 1938.

PAREDES CHAVES, José Ignacio. El médico veterinario en la salud pública. Bogotá: [s.n.], 1954.

POHL-VALERO, Stefan. The scientific lives of chicha: the production of a fermented beverage and the making of expert knowledge in Bogotá, 1889-1938. Osiris, v.35, p.204-227, 2020.

POHL-VALERO, Stefan. Alimentación, raza, productividad y desarrollo. Entre problemas sociales nacionales y políticas nutricionales internacionales (Colombia, 1890-1940). In: Mateos, Gisela; Suárez-Díaz, Edna. Aproximaciones a lo local y lo global: América Latina en la historia de la ciencia contemporánea. Ciudad de México: Centro de Estudios Filosóficos, Políticos y Sociales Vicente Lombardo Toledano, 2016. p.115-154.

POHL-VALERO, Stefan. "La raza entra por la boca": energy, diet, and eugenics in Colombia, 1890-1940. Hispanic American Historical Review, v.94, n.3, p.455-486, 2014.

POHL-VALERO, Stefan et al. Cartografía del gobierno alimentario en Colombia durante los inicios del desarrollo, 1938-1960. In: Pohl-
Valero, Stefan; Vargas Domínguez, Joel. $E l$ hambre de los otros: ciencia y políticas alimentarias en Latinoamérica, siglos XX y XXI. Bogotá: Editorial de la Universidad del Rosario, 2021.

POHL-VALERO, Stefan; VARGAS, Joel. El hambre de los otros: reflexiones sobre los ensamblajes del gobierno alimentario en América Latina. In: Pohl-Valero, Stefan; Vargas Domínguez, Joel. El hambre de los otros: ciencia y políticas alimentarias en Latinoamérica, siglos XX y XXI. Bogotá: Editorial de la Universidad del Rosario, 2021.

PROPOSICIONES aprobadas por la comisión general del Concejo. Registro Municipal, v.69, n.385-389, p.80-81, 1949.

PROTECCIÓN materna e infantil. La leche en polvo como factor en la campaña contra las diarreas y enteritis de la infancia. Boletín Informativo - Órgano de la Dirección de Higiene del Municipio de Bogotá, v.2, n.12, p.14-15, 1948.

PUBLICIDAD de General Electric. El Tiempo, p.15, 20 ago. 1952.

PUBLICIDAD de ordeñadoras Clean-Easy. Agricultura Tropical, v.2, n.7, p.38, 1946.

QUÉ OPINAN las amas de casa sobre el alza general de los artículos. El Tiempo, p.3, 16 feb. 1955.

RESOLUCIÓN número 9 de 1948. Boletín Informativo - Órgano de la Dirección de Higiene del Municipio de Bogotá, v.2, n.16, p.15-17, 1948.

ROJAS, Tiberio; IBÁÑEZ, Pedro M. Contribución al estudio de la higiene pública en Bogotá. Registro Municipal de Higiene, número extraordinario, p.3-55, 1919.

ROMÁN, Gustavo. Observaciones sobre la industria lechera en la Sabana de Bogotá. Revista de la Facultad de Medicina Veterinaria, v.15, n.90, p.42-47, 1946.

SAAVEDRA, Pedro Nel. La leche. Cuestión de vida o muerte. Salud, v.11, n.41-53, p.416-420, 1951.

SANDILANDS, Roger. The Lauchlin Currie Papers at Duke University: a review of their significance for the history of political economy. Paper presented at the History of Economics Society conference at Duke University. Durham, 2003.

STEINER, Jorge. Sugestiones para el control de leches. Agricultura Tropical, v.6, n.9, p.43-47, 1950.

TURRIAGO ROMERO, Bernardo. Cuatro años de observaciones profesionales al servicio de la Secretaría de Higiene de Bogotá. Revista de la Facultad de Medicina Veterinaria, v.21, n.113, p.358-375, 1955. 
VALENZE, Deborah. Milk. A local and global history. New Haven: Yale University Press, 2011.

WYLIE, Kathryn H. The Agriculture of Colombia. Washington: US Department of Agriculture, 1942.
ZAZUETA, María del Pilar. Milk against poverty: nutrition and the politics of consumption in twentieth-century Mexico. Thesis (PhD) Columbia University, New York, 2011.

\section{$\rightarrow \rightarrow \rightarrow<<<$}

